\section{Comments on Schreiner and Jenkins and Schreiner}

\author{
By L. D. Calvert \\ 77 Seaview Parade, Lakes Entrance, Victoria 3909, Australia
}

Excellent earlier articles (Schreiner, 1986; Jenkins and Schreiner, 1986) provide a sound basis for operating any powder diffractometer. This comment describes three simple, but basic procedures worth emphasizing in the context of these earlier papers.

(1) A standard specimen should be thoroughly examined on every diffractometer after any alignment or disturbance, and then briefly reexamined, frequently in any routine laboratory, or before and after every set of experiments in a research laboratory. Silicon, silver and tungsten powders give good simple patterns while $\mathrm{As}_{2} \mathrm{O}_{3}$ and $\mathrm{LaB}_{6}$ give convenient patterns with more lines. Quartz and $\mathrm{KBF}_{4}$ give patterns with closely spaced lines which are useful for judging resolution. It is most important that literature values for lattice parameters, and hence the theta-values, should not be

\section{Departments}

Ron Anderson, Editor

Calendar of Meetings: Organizers of scientific meetings wishing to inform the readers of Powder Diffraction of their plans are welcome to submit meeting announcements to the Departments Editor. The announcements may be accompanied by text giving particulars of the meeting and programs. The additional matter in such expanded announcements will be printed on a space-available basis. While we will accept announcements of meetings on topics even remotely related to powder diffraction as a service to our readers, the editors, at their discretion, reserve the right to reject announcements of meetings concerning totally unrelated subjects. The deadlines in the instructions to authors apply to meeting announcements. There is no charge for this service. Meeting organizers wishing to purchase advertisements are invited to contact Powder Diffraction's Advertising Manager.

Commercial Announcements: This column is reserved for the commercial use of individuals and firms providing products or services to the powder diffraction community. Press releases and new product announcements are appropriate and welcome. The insertions, up to 300 words or the equivalent if a figure is included, should give a price, if appropriate, and the contributor's full name and address. Full or partial inclusion will be on a space-available basis at the editor's discretion, with preference given to advertising agencies and companies that purchase advertisements in Powder Diffraction. Send contributions to the Departments Editor. Powder Diffraction can assume no liability for the accuracy of the claims made. accepted until the parameters for that particular sample have been verified adequately. This is especially so for those phases prone to form solid solutions (quartz, $\mathrm{KBF}_{4}$ ).

(2) A low intensity and physiologically safe radioactive source of X-rays should be used for regular checks. This, when placed directly on the face of the counter, checks all components of the counting chain independently of other parts of the total system.

(3) A simple check of backlash, and later, wear is possible by placing any front-surfaced mirror (a microscope slide will do) in the specimen mount with the diffractometer set at any convenient angle in the area of most interest. Place a sharply defined light source in a fixed position so as to reflect onto a scale placed on the wall or ceiling (graph paper or a small ruler will do) a few meters away. By resetting to the same angle, quickly and slowly, from higher and lower angles, backlash and reproducibility, and later, wear can be established on an arbitrary scale. These can be checked in a few minutes on a routine basis if the light source and the scale are left in position.

Jenkins, R. and Schreiner, W. N. (1986). Powder Diffraction, 1, 305-319. Schreiner, W. N. (1986). Powder Diffraction, 1, 26-33.
Short Courses and Workshops: This journal will print announcements of short courses and workshops in fields relating to the interests of its readers. Organizers of such programs are invited to send short descriptive announcements to the Departments Editor. See below for typical contributions that will be printed free of charge. The editors reserve the right to determine suitability for printing with regard to course or workshop content.

Calendar of Meetings

JCPDS-ICDD Subcommittee Activities

Short Coursés and Workshops

Book Reviews

General Announcements

Computer Comments 